\title{
Risk of polio reintroduction to border regions of Islamic Republic of Iran: seroprevalence study of children with at least 5 doses of oral polio vaccine
}

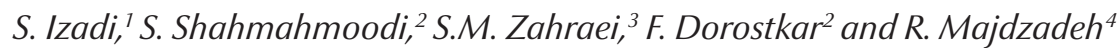

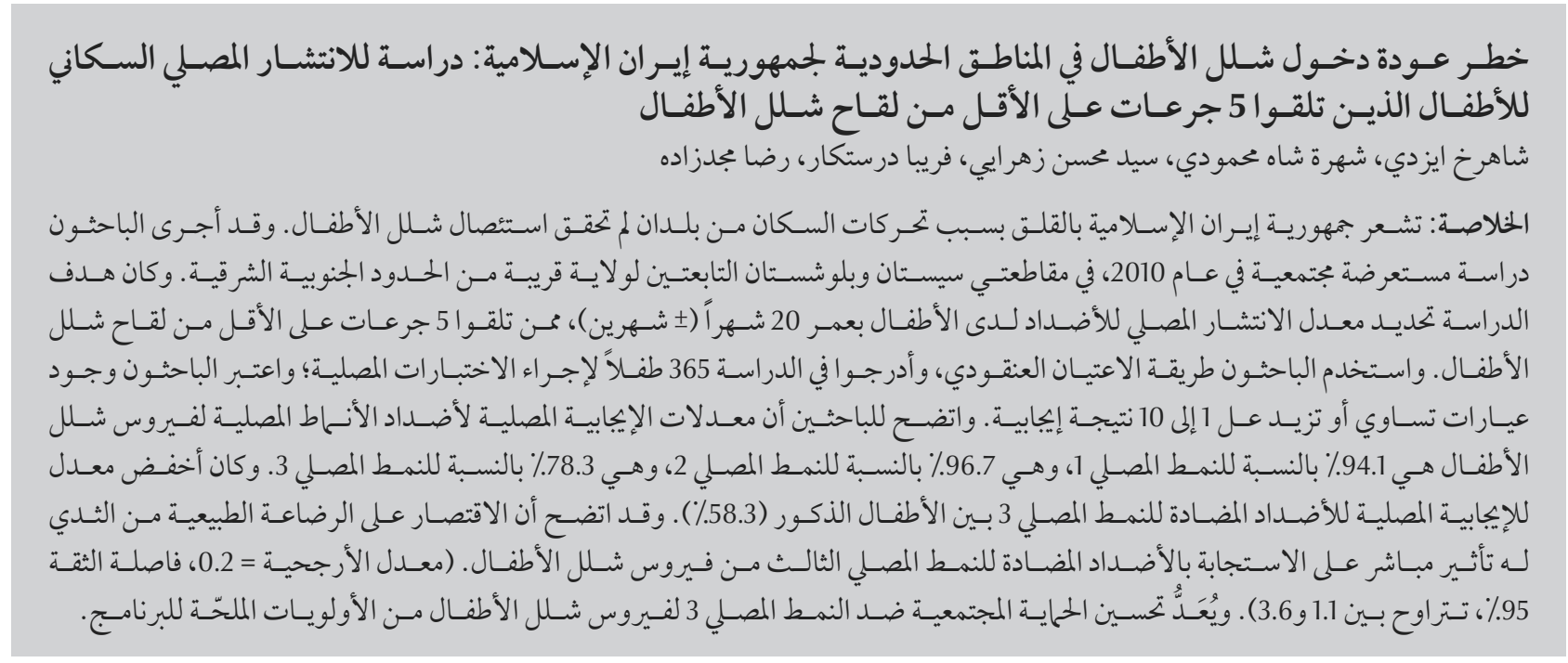

ABSTRACT Movements of populations from countries where polio has not been eradicated is a concern in the Islamic Republic of Iran. A cross-sectional, community-based study was implemented in 2010 in 2 districts in Sistan-va-Baluchestan Province near the south-east border. The aim was to determine the seroprevalence of antibodies in children aged $20( \pm$ 2) months who had received at least 5 doses of trivalent oral polio vaccine. Using cluster sampling, 365 children were enrolled for serological testing. Antibody titres $\geq 1: 10$ were considered positive. Seropositive rates for antibody against poliovirus serotypes 1, 2 and 3 were 94.1\%, 96.7\% and 78.3\% respectively. The lowest seropositive rate was for antibody against polio serotype 3 (PV3) among boys (58.3\%). Exclusive breastfeeding showed a direct relationship with antibody response to $\mathrm{PV} 3(\mathrm{OR}=2.0 ; 95 \% \mathrm{Cl}$ : 1.1-3.6). Improving community protection against $\mathrm{PV} 3$ is an urgent programme priority.

Risque de réintroduction de la poliomyélite dans les régions frontalières de la République islamique d'Iran : étude de la séroprévalence chez des enfants ayant reçu au moins cinq doses du vaccin antipoliomyélitique oral

RÉSUMÉ Les déplacements de population en provenance d'autres pays où la poliomyélite n'a pas été éradiquée représentent une préoccupation en République islamique d'Iran. Une étude transversale communautaire a été menée en 2010 dans deux districts de la province du Sistan-Balouchistan près de la frontière du sud-est. L'objectif était de déterminer la séroprévalence des anticorps chez des enfants âgés de 20 ( \pm 2 ) mois qui avaient reçu au moins cinq doses du vaccin antipoliomyélitique oral trivalent. L'échantillonnage en grappes était la méthode utilisée ; 365 enfants ont été recrutés pour une analyse sérologique. Des titres d'anticorps supérieurs ou égaux à 1:10 étaient considérés comme positifs. Les taux de séropositivité pour les anticorps dirigés contre les sérotypes des poliovirus 1, 2 et 3 étaient de $94,1 \%, 96,7 \%$ et 78,3\%, respectivement. Le taux de séropositivité le plus faible était celui correspondant aux anticorps contre le sérotype 3 du poliovirus chez les enfants de sexe masculin (58,3\%). L'allaitement au sein exclusif présentait un lien direct avec la réponse des anticorps au sérotype 3 du poliovirus $(O R=2,0 ; I C$ à $95 \%: 1,1-3,6)$. Améliorer la protection de la communauté contre le sérotype 3 du poliovirus représente une priorité programmatique urgente.

${ }^{7}$ Health Promotion Research Centre, School of Public Health, Zahedan University of Medical Sciences, Zahedan, Islamic Republic of Iran (Correspondence to S. Izadi: izadish@yahoo.com). ${ }^{2}$ Department of Virology; ${ }^{4}$ Department of Epidemiology, School of Public Health, Tehran University of Medical Sciences, Tehran, Islamic Republic of Iran. ${ }^{3}$ Centre for Communicable Disease Control, Ministry of Health and Medical Education, Tehran, Islamic Republic of Iran.

Received: 25/06/13; accepted: 18/12/13 


\section{Introduction}

The polio eradication programme was initiated by the World Health Organization (WHO) in 1988 and the Islamic Republic of Iran joined the campaign in 1991. In 2001, after 10 years of high coverage of routine immunization, supplementary immunization activities and watchful surveillance of acute flaccid paralysis (AFP), the country became polio-free [1]. Among nearby and neighbouring countries India was the most recent country that celebrated 1 full year with no new reported cases and has been considered polio-free since February 2012 $[2,3]$. However, the Islamic Republic of Iran shares borders with Afghanistan and Pakistan, 2 of the 3 countries that have not yet been able to stop wild poliovirus circulation. Until polio has been eliminated in a country there is a sustained threat to all nearby countries, especially those which have common borders, as it was the case with China in 2011, when importation from Pakistan lead to the occurrence of an outbreak with 21 cases of wild poliovirus serotype 1 (PV1). That was the first wild poliovirus outbreak reported in the WHO Western Pacific Region since 1997 [3].

Continuous movement of people across borders, especially in the southeast region of the Islamic Republic of Iran-which is less developed compared with other parts of the country-has always been worrisome for the Iranian Ministry of Health. The last polio cases reported were 3 cases in 2001, all serotype 1, all imported from Pakistan to Chabahar district in Sistanva-Baluchestan Province. Since then no other cases have been reported. Based on surveillance data, in 2010 the vaccination coverage of oral polio vaccine (OPV) in the Province was about 97\%, and the rate of non-polio AFP cases per 100000 population aged $<15$ years was 2.5 (i.e. 25 non-polio AFP cases) [4]. To evaluate community protection against infiltration of the wild poliovirus from the other side of the border, this study was implemented in Sistan-vaBaluchestan Province to determine the seroprevalence of antibodies to poliovirus in 20-month-old children vaccinated by at least 5 doses of trivalent OPV.

\section{Methods}

A cross-sectional, community-based study was implemented at the end of 2010 in 2 districts in the north and south of Sistan-va-Baluchestan Province, Islamic Republic of Iran. The field stage of the study began on 22 December 2010 simultaneously in both districts and continued for about 10 days. The study protocol was reviewed and approved by the Committee for Medical Research Ethics of Zahedan University of Medical Sciences.

\section{Background to the study}

\section{Iranian national immunization programme}

Based on the Iranian national immunization schedule, by the end of the 18th month of age, all children must have received at least 5 doses of OPV, scheduled at birth, 2, 4, 6 and 18 months. There is also a last 6th dose that all children have to receive before school entry (at 4-6 years of age). This schedule has been fairly constant within the past 10 years. In addition, each year in January and again in February, all children $<5$ years of age have another chance to receive 2 additional supplementary doses during national immunization days. All OPV in Islamic Republic of Iran are produced by Razi Vaccine and Serum Research Institute in Tehran and all children who participated in this study had been vaccinated by trivalent OPV, i.e. live poliovirus serotypes 1,2 and 3 (PV1, PV2 and PV3), from the same source.

\section{Study setting}

Sistan-va-Baluchestan Province, with a population composed of a mixture of urban (1 193198 people), rural (1 206547 people) and nomads (5 997 people), is located in the south-east of Islamic Republic of Iran, and has common borders and strong cultural ties with Pakistan and Afghanistan [5]. Despite the widely scattered population, in most districts the coverage of primary health care services, which includes routine immunizations, is above $90 \%$ both in rural and urban areas. Nevertheless, there are still hard-to-reach villages with small populations, and nomads with moving populations that are more vulnerable to any health treats.

The present study was implemented in the urban and rural regions of $\mathrm{Za}$ hedan in the north and Chabahar in the south, 2 districts located about $700 \mathrm{~km}$ away from each other in Province. Based on the latest published census results, the population of Zahedan district is 681460 (585 842 urban, 95434 rural and 184 nomads) and those of Chabahar district 216681 (77 128 urban, 139553 rural and no nomads) [5].

\section{Sample}

\section{Target population}

The target population for this study were all children within the age range of $20( \pm 2)$ months (born from 22 February 2009 to 25 June 2009) living in Zahedan and Chabahar districts. The other inclusion criterion was a recorded history of receiving 5 OPV doses based on the national immunization schedule (regardless of the twice per year national immunization days).

\section{Sampling scheme}

Using reports from similar countries on seroconversion rates after OPV vaccination of about $88 \%$ (in Gambia) to 95\% (in China) [6,7], we estimated a seroprevalence of about $85 \%$ in the study population. Considering the estimation confidence interval (CI) of $95 \%$ and the estimation error (i.e. 
the difference between estimate and parameter that we were willing to tolerate) equal to 0.085 , the required sample size was 68 children in each stratum [8]. Since Zahedan, the capital city of the Province, is more developed and is located about $700 \mathrm{~km}$ north of Chabahar, and since its population is almost 3 time that of Chabahar, we separated them in sampling. To ensure that the rural areas in each district had sufficient representation in the sample we also considered a separate stratum for urban and rural areas. Therefore, based on 4 strata for sampling (2 rural and 2 urban strata for Zahedan and Chabahar districts separately), the total sample size came to 280 . However, since we were using the probability proportional to size cluster sampling method recommended by WHO for evaluation of vaccination coverage, we considered a sampling design effect equal to 1.5 , in which the final sample size was 420 cases ( 105 for each layer) [9].

In both urban and rural areas there are complete lists of the households booked in each health centre. The cluster size was defined as at least 5 children eligible for the serological part (i.e. 21 clusters in each stratum) and in each cluster location, interviews and blood sampling were continued until the 5 children had been blood sampled. Using the results of the latest national census performed in 2006-07, cluster locations were defined for urban and rural parts of each district. In each stratum a cumulative list of the study population was produced and a systematic sample was selected from a random start. By dividing the total population of the communities by the number of communities to be selected in each stratum (i.e. 21 communities) the sampling interval was obtained. A random number between 1 and the result of the division was then chosen. This was fitted into position in the list to identify the first community in the sample. Then by adding the sampling interval to the initial random number the remaining communities were selected. In both these districts there is an almost complete health register of all households and household members. We considered the dimension of each community to be 200 people. From each selected community we chose 5 subjects at random [9].

\section{Data collection}

The research teams comprised a nurse trained in blood sampling of children, an interviewer trained in using the study research questionnaire and a driver.

\section{Household visits}

Households were the primary sampling units. In each location, 5 households with children in the required age range were selected randomly using a table of random numbers from the log book of the health centre. Then the selected households were visited one by one searching for eligible children. The study questionnaire was filled during an interview with one of the parents (usually the mother) by an interviewer adept in the local language. If there were 2 eligible children in the same household, the interview was performed only for the younger one. If at the end of the interview, if the child was recognized as eligible for the serological part of the study based on the records in his/ her vaccination card, a blood sample was taken. In the absence of parental consent to blood sampling the child was replaced by another one selected by the same method, while the information of the replaced child was kept for the sake of statistical analysis and comparison with other children.

\section{Questionnaire}

In addition to the demographic information such as sex, age and birth date, a full vaccination history based on the records of both the vaccination card and vaccination log books of the health houses was included in the questionnaire. The other important variables were feeding history in the first 6 months of life (exclusive breastfeeding or other choices), education level and occupation of the parents, and selected economic indices, including the number of rooms, household size, possession and availability of furniture (e.g. air conditioners, refrigerator, mobile and fixed phone, oven, television, washing machine, vacuum cleaner, and computer), internet availability and possession of motorcycle or any other kind of vehicle.

\section{Laboratory methods}

Serum samples were screened for neutralizing antibody against PV1, PV2 and PV3 by micro-neutralization assay, which was performed by an in-house procedure according to $\mathrm{WHO}$ guidelines, with slight modifications [10].

Briefly, sera were inactivated at $56^{\circ} \mathrm{C}$ for 30 minutes before the test, diluted 2-fold from 1:10 to 1:1280, and then incubated for 2 hours at $36^{\circ} \mathrm{C}$ with equivalent volume of $100 \mathrm{TCID}_{50}$ [tissue culture dose to inhibit 50\%] of PV1, PV2 or PV3. After the incubation period, $50 \mu \mathrm{L}$ of L20B cell line $\left(2 \times 10^{4}\right.$ cells $/ 0.1 \mathrm{~mL}$ ) was added to all the micro titre plate wells (including cell control wells to monitor uninfected cell viability). Each test serum was investigated in triplicate. A back-titration of the 3 serotypes was included in each run as a control. After incubation for 5 days, the highest dilution of serum that prevented the development of virus-induced cytopathogenic effects was recorded. A serum sample was considered positive if antibodies were present at a dilution $1: \geq 10$ of the serum specimen. To calculate geometric mean titre (GMT) seronegative reports (titres $<1: 10$ ) were considered as equal to 1:2.

\section{Analysis}

A computerized data bank was produced based on the completed questionnaires and the data were analysed using SPSS, version 15, and STATA, version 9.0. In addition to descriptive tables, we used the chi-squared and Mann-Whitney tests for data analysis, 
and the odds ratios $(\mathrm{OR})$ for univariate analysis [11].

\section{Results}

\section{Eligible sample}

Table 1 shows the sampling profile of the children in relation to vaccination status. Only $88.1 \%$ of the expected sample was fulfilled in Zahedan and 56.7\% in Chabahar. A total of 75 children were excluded from the study; 48 were eligible with respect to their vaccination card records (15 in Chabahar and 33 in Zahedan) but were excluded due to the lack of a blood sample, and 27 children were excluded because they had received less than 5 doses of OPV. There were no reports of refusal to participate in either of the 2 districts, and failure in blood sampling was due to technical problems in drawing blood.

The mean age of the children eligible for blood sampling was 20.2 months (standard deviation $=1.3)$. The age of 27 of the participants (10 in Zahedan and 17 in Chabahar) was above 22 months. However, we decided to keep them in the sample and so the youngest participant was 18.6 months and the oldest 23.8 months. Most interviews were performed with mothers (78\% in Chabahar and $86 \%$ in Zahedan); the remainder were performed with another first-degree relative.

In both districts 61 children who were not eligible for the serological part of the study were also blood sampled (due to some misunderstanding of nurses about the study protocol especially in Chabahar). Of these children 53 were from Chabahar and 8 from Zahedan; 52 had recorded history of receiving 4 doses of OPV, 6 had received 3 OPV, 2 had received 2 OPV and 1 had received only 1 dose. Even though it affected the sampling scheme of the study, this mistake in allocation of children provided an opportunity to study the serological response of children to only 4 doses of vaccine.

\section{Serological results}

Table 2 shows the results of serological tests. The overall seropositive rates for antibody against PV1, PV2 and PV3 were $94.1 \%, 96.7 \%$ and $78.3 \%$ respectively. The seroprevalence of antibody against PV3 was higher in Zahedan than Chabahar and in urban than rural regions. The seroprevalence of antibodies to PV3 was lower than antibodies to the other 2 poliovirus serotypes. The seroprevalence of antibodies against PV1 and PV2 among fully vaccinated children was above $90 \%$ in rural and urban areas of both districts, whereas seroprevalence against PV3 was below $90 \%$ in most subgroups, except in the urban areas of Zahedan. In the rural areas of Chabahar the seroprevalence of antibodies against PV 3 was $60.3 \%$. The last 2 rows of Table 2 show that the seroprevalence of antibodies against PV1 and PV2 in children who were not fully vaccinated were comparable with that of fully vaccinated children.

\section{Serological results by sex}

Table 3 shows the serological results by sex of the children. The male:female ratio of all participants in the samples of the districts, taken together, was 6:4. The lowest seropositive rate for antibody against PV3 was observed among male children in Chabahar district (58.3\%). The PV3 seronegative rate was significantly higher in males than in females (26.0\% versus $16.3 \%$ ) $(\mathrm{OR}=1.8 ; 95 \% \mathrm{CI}: 1.0-3.2)$ and this difference was greater in Chabahar ( $41.7 \%$ versus $25.5 \%$ ) than Zahedan (14.4\% versus $11.4 \%)$. Even when we add those 44 participants in Chabahar who had received only 4 OPV (1 dose less than the other participants) there was still a difference in the seropositive rate between males and females $(53.2 \%$ versus $66.7 \%$ respectively $)(\mathrm{OR}=1.8$; 95\% CI: 0.9-3.4; $P=0.084)$.

There were no difference sin serological status between males and females with regard to age distribution ( $t$-test; $P=0.816$ ), place of living (urban versus rural) $(\mathrm{OR}=1.7$; 95\% CI: $0.8-$ 3.7) and socioeconomic factors such as father's education $(P=0.350)$, mother's education $(P=0.507)$, household size $(P=0.631)$ or vehicle ownership $(P=$ 0.183 ) [data not shown].

\section{Geometric mean antibody titres}

Table 4 shows the GMTs of antibodies against the 3 polio serotypes presented separately and by urban/rural region. The difference between the GMT of urban and rural regions was tested

\begin{tabular}{|c|c|c|c|c|c|}
\hline \multirow[t]{3}{*}{ Vaccination status of child } & \multicolumn{2}{|c|}{ Zahedan } & \multicolumn{2}{|c|}{ Chabahar } & \multirow{3}{*}{$\begin{array}{l}\text { Total } \\
\text { No. }\end{array}$} \\
\hline & $\begin{array}{c}\text { Blood } \\
\text { sampled }\end{array}$ & $\begin{array}{l}\text { No blood } \\
\text { sampled }\end{array}$ & $\begin{array}{c}\text { Blood } \\
\text { sampled }\end{array}$ & $\begin{array}{l}\text { No blood } \\
\text { sampled }\end{array}$ & \\
\hline & No. & No. & No. & No. & \\
\hline At least 5 recorded OPV vaccinations & 185 & 33 & 119 & 15 & 352 \\
\hline Less than 5 recorded OPV vaccinations & 8 & 20 & 53 & 7 & 88 \\
\hline Total & 193 & 53 & 172 & 22 & 440 \\
\hline
\end{tabular}

$O P V=$ oral polio vaccine. 


\begin{tabular}{|c|c|c|c|c|c|c|c|}
\hline \multirow[t]{2}{*}{ District/area } & \multirow[t]{2}{*}{$\begin{array}{l}\text { No. of } \\
\text { received } \\
\text { OPV }\end{array}$} & \multirow[t]{2}{*}{$\begin{array}{l}\text { No. of } \\
\text { children }\end{array}$} & \multirow{2}{*}{$\begin{array}{c}\text { Seropositive for } \\
\text { PV1 } \\
\%(95 \% \mathrm{Cl})\end{array}$} & \multirow{2}{*}{$\begin{array}{c}\text { Seropositive for } \\
\text { PV2 } \\
\%(95 \% \mathrm{Cl})\end{array}$} & \multirow{2}{*}{$\begin{array}{l}\text { Seropositive } \\
\quad \text { for PV3 } \\
\%(95 \% \mathrm{Cl})\end{array}$} & \multirow{2}{*}{$\begin{array}{l}\text { Seropositive } \\
\text { for all } 3 \\
\text { serotypes } \\
\%(95 \% \mathrm{Cl})\end{array}$} & \multirow{2}{*}{$\begin{array}{c}\text { Seronegative } \\
\text { for all } 3 \\
\text { serotypes } \\
\%(95 \% \mathrm{Cl})\end{array}$} \\
\hline & & & & & & & \\
\hline \multicolumn{8}{|l|}{ Zahedan } \\
\hline Urban & 5 & 101 & 92.1 (86.8-97.3) & $94.1(89.1-99.0)$ & $90.1(83.3-96.9)$ & $80.2(71.7-88.7)$ & $1.0(0.0-2.9)$ \\
\hline Rural & 5 & 84 & $95.2(89.8-100.0)$ & $96.4(92.8-100.0)$ & $83.3(76.4-90.3)$ & $79.8(73.3-86.2)$ & $0.0(-)$ \\
\hline Total & 5 & 185 & 93.5 (89.7-97.3) & 95.1 (91.9-98.3) & $87.0(82.1-92.0)$ & $80.0(74.5-85.5)$ & $0.5(0.0-1.6)$ \\
\hline \multicolumn{8}{|l|}{ Chabahar } \\
\hline Urban & 5 & 41 & 97.6 (93.1-100.0) & $100.0(-)$ & $73.2(56.2-90.1)$ & 70.7 (51.0-90.4) & $0.0(-)$ \\
\hline Rural & 5 & 78 & $93.6(88.7-98.4)$ & 98.7 (96.2-100.0) & $60.3(47.5-73.0)$ & $56.4(45.1-67.7)$ & $0.0(-)$ \\
\hline Total & 5 & 119 & $95.0(91.4-98.5)$ & 99.2 (97.5-100.0) & $64.7(54.4-75.0)$ & $61.3(51.2-71.5)$ & $0.0(-)$ \\
\hline \multicolumn{8}{|l|}{ Both districts } \\
\hline Urban & 5 & 142 & 93.7 (89.7-97.7) & 95.8 (92.1-99.4) & $85.2(77.9-92.5)$ & 77.5 (69.1-85.9) & $0.7(0.0-2.0)$ \\
\hline Rural & 5 & 162 & $94.4(90.7-98.1)$ & 97.5 (95.2-99.8) & $72.2(64.1-80.3)$ & $68.5(61.2-75.8)$ & $0.0(-)$ \\
\hline Total & 5 & 304 & 94.1 (91.4-96.8) & 96.7 (94.6-98.8) & $78.3(72.6-84.0)$ & $72.7(67.1-78.3)$ & $0.3(0.0-1.0)$ \\
\hline \multicolumn{8}{|l|}{$\begin{array}{l}\text { Non-eligible } \\
\text { children }^{a}\end{array}$} \\
\hline Total sample & 4 & 52 & $98.1(94.3-100.0)$ & $98.1(94.4-100.0)$ & $50.0(36.1-63.9)$ & $48.1(32.9-63.2)$ & $0.0(-)$ \\
\hline Total sample & $<4$ & 9 & $88.9(67.0-100.0)$ & $100.0(-)$ & 77.8 (55.9-99.6) & 77.8 (55.9-99.6) & $0.0(-)$ \\
\hline
\end{tabular}

${ }^{a}$ Children with history of $<5$ recorded OPV received.

$\mathrm{Cl}=$ confidence interval; $O P V=$ oral polio vaccine; $P V 7=$ poliovirus serotype 1; $P V 2=$ poliovirus serotype $2 ; P V 3=$ poliovirus serotype 3 .

using both independent sample $t$-test and Mann-Whitney test. There were clear differences in GMT between the 2 areas for PV1 and PV3 response but this only reached statistical significance for PV3 $(P=0.027)$. Comparisons between the 2 districts and between the urban and rural regions within each district showed no significant differences. GMT comparisons between the 2 sexes were also not significant [data not shown].

\section{Exclusive breastfeeding and antibody response}

One of the questions that we asked in interviews was about exclusive breastfeeding during the first 6 months of life. This was the only variable in the interviews that showed a positive relationship with antibody response to PV3 (Table 5). Compared with the other mentioned feeding groups, the probability of being seropositive for anti-PV3 antibody was twice as high among children who had been exclusive breastfed during the first 6 months of life.

\section{Discussion}

In both districts the seroprevalence of antibodies against PV1 and PV2 among fully vaccinated children were above $90 \%$ but that of PV3 was below $90 \%$, except in urban areas of Zahedan. In the rural areas of Chabahar, however, the anti-PV3 seroprevalence was only about $60 \%$, and this is a concern when we bear in mind that our study population were children in their 2 nd year of life, i.e. the most vulnerable and the most important target group for protection. In view of the continuous movement of populations between the Islamic Republic of Iran and Pakistan border (for social and commercial purposes) and the poor sanitary conditions of the rural areas (without proper water supplies) coupled with poor health behaviours in the early childhood years, it could be concluded that the persistence of such low protection might sooner or later lead to polio outbreaks.

There are some points to be kept in mind with regard to interpretation of our serological results, and also with regard to the number of received doses of OPV in the study population. The birth dates of the sample were between 22 February 2009 and 25 June 2009. As mentioned before, in Iranian Ministry of Health implements national immunization days biannually in all the border regions and performs a "mopping up" phase in the rural areas. Within the time interval from the birth date of the eldest child and the implementation date of this study, 2 national immunizations was performed (in January and February 2010). However, since the vaccine that was administered during the national immunization days were not recorded anywhere, we did not count them in calculation of the number of received vaccines for the children in 


\begin{tabular}{|c|c|c|c|c|c|c|}
\hline \multirow[t]{2}{*}{ District/seropositivity } & \multicolumn{2}{|c|}{ Male } & \multicolumn{2}{|c|}{ Female } & \multirow[t]{2}{*}{ OR $(95 \% \mathrm{CI})^{\mathrm{b}}$} & \multirow[t]{2}{*}{$P$-value } \\
\hline & No. & $\%$ & No. & $\%$ & & \\
\hline \multicolumn{7}{|l|}{ Zahedan } \\
\hline Seropositive for PV1 & 87 & 89.7 & 86 & 97.7 & $4.9(1.1-23.2)$ & 0.027 \\
\hline Seropositive for PV2 & 92 & 94.8 & 84 & 95.5 & $1.1(0.3-4.4)$ & 0.847 \\
\hline Seropositive for PV3 & 83 & 85.6 & 78 & 88.6 & $1.3(0.5-3.1)$ & 0.535 \\
\hline Total $^{\text {a }}$ & 97 & - & 88 & - & & \\
\hline \multicolumn{7}{|l|}{ Chabahar } \\
\hline Seropositive for PV1 & 71 & 98.6 & 42 & 89.4 & $0.12(0.0-1.0)$ & 0.024 \\
\hline Seropositive for PV2 & 72 & 100.0 & 46 & 97.9 & - & 0.214 \\
\hline Seropositive for PV3 & 42 & 58.3 & 35 & 74.5 & $2.1(0.9-4.7)$ & 0.072 \\
\hline Total $^{\mathrm{a}}$ & 72 & - & 47 & - & & \\
\hline \multicolumn{7}{|l|}{ Both districts } \\
\hline Seropositive for PV1 & 158 & 93.5 & 128 & 94.8 & $1.3(0.5-3.4)$ & 0.627 \\
\hline Seropositive for PV2 & 164 & 97.0 & 130 & 96.3 & $0.8(0.2-2.8)$ & 0.717 \\
\hline Seropositive for PV3 & 125 & 74.0 & 113 & 83.7 & $1.8(1.0-3.2)$ & 0.041 \\
\hline Total $^{\mathrm{a}}$ & 169 & - & 135 & - & & \\
\hline
\end{tabular}

${ }^{a}$ Total no. of children in layer ${ }^{b}$ Univariate odds ratio.

$\mathrm{Cl}=$ confidence interval; $\mathrm{PVI}=$ poliovirus serotype $1 ; \mathrm{PV} 2$ = poliovirus serotype $2 ; \mathrm{PV} 3$ = poliovirus serotype 3 .

this study (for the sake of precision and validity of the data).

In both districts, the seroprevalence of antibodies to PV3 was lower than antibodies to PV1 and PV2. Since the immunogenic substance for all 3 types of OPV came from the same manufacturer, problems of cold-chain or problems with vaccination techniques did not seem to be an appropriate explanation for lower seroconversion rates against PV3. If these had been the cause, the antibody level against the other 2 poliovirus serotypes should also be low. Such a difference between the seroprevalence of antibodies to PV3 and the other 2 polio serotypes is not unique to our country and has been reported from other countries (both developing and developed). However, none of them have presented an acceptable explanation for the difference between antibody response to PV3 and the other 2 poliovirus serotypes [12-17]. We think this finding, which suggests that the immunogenicity of PV3 might be less than the other 2 polio serotypes, deserves further investigation, especially from the immunological perspective.

During the 1999 outbreak of poliomyelitis in India, out of 1126 virologically confirmed cases, 719 (64\%) cases were due to PV3 [14]. The danger of low community protection against PV3, especially for communities that have a high exchange rate with potentially

\begin{tabular}{|c|c|c|c|c|c|}
\hline Virus type/area & No. of children & $\begin{array}{l}\text { Geometric } \\
\text { mean titre }\end{array}$ & $\begin{array}{c}P \text {-value } \\
\text { (independent } t \text {-test) }\end{array}$ & Mean rank & $\begin{array}{c}P \text {-value } \\
\text { (Mann-Whitney test) }\end{array}$ \\
\hline \multicolumn{6}{|l|}{ PVI } \\
\hline Urban & 142 & 117 & 0.148 & 162 & \multirow{2}{*}{0.075} \\
\hline Rural & 162 & 88 & & 144 & \\
\hline \multicolumn{6}{|l|}{ PV2 } \\
\hline Urban & 142 & 120 & 0.823 & 152 & \multirow{2}{*}{0.937} \\
\hline Rural & 162 & 125 & & 152 & \\
\hline \multicolumn{6}{|l|}{ PV3 } \\
\hline Urban & 142 & 43 & 0.023 & 164 & \multirow{2}{*}{0.027} \\
\hline Rural & 162 & 26 & & 142 & \\
\hline
\end{tabular}

$P V 1$ = poliovirus serotype 1; $P V 2$ = poliovirus serotype 2; $P V 3=$ poliovirus serotype 3. 


\begin{tabular}{|c|c|c|c|c|c|c|}
\hline \multirow[t]{2}{*}{ Method of feeding in first 6 months } & \multicolumn{2}{|c|}{ Seropositive for PV3 } & \multicolumn{2}{|c|}{ Seronegative for PV3 } & \multirow[t]{2}{*}{ OR $(95 \% \mathrm{Cl})^{\mathrm{a}}$} & \multirow[t]{2}{*}{$P$-value } \\
\hline & No. & $\%$ & No. & $\%$ & & \\
\hline Exclusive breastfeeding & 187 & 78.6 & 43 & 65.2 & $2.0(1.1-3.6)$ & 0.025 \\
\hline Other feeding ${ }^{\mathrm{b}}$ & 51 & 21.4 & 23 & 34.8 & & \\
\hline
\end{tabular}

${ }^{a}$ Univariate odds ratio; Including: breastfeeding accompanied with feeding with powder milk; breastfeeding accompanied with feeding with cow's milk; exclusive feeding with powder milk; exclusive feeding with cow's milk.

$O R=$ odds ratio; $C I=$ confidence interval; $P V 3=$ poliovirus serotype 3 .

infecting communities, has been noticed in other studies, and such a threat has to be taken seriously and managed appropriately $[12,15,17]$.

It is worth mentioning that there have also been some studies showing that, even though the seroprevalence of antibodies to PV3 is still lower than the other 2 serotypes, the difference is not large $[13,18,19]$. There is some evidence that using monovalent vaccines may cover the problem of lower seroconversion rates of polio serotypes, as reported during a meticulous study in Nigeria of monovalent type $1 \mathrm{OPV}$ [20].

We also found a large difference in the seroprevalence of antibody against PV3 between Zahedan and Chabahar and also between the rural and urban regions of Chabahar. The analysis of GMTs against the poliovirus serotypes (which provides data not only about the positive or negative range of antibody level, but the antibody level itself) also showed a significant difference in PV3 antibody titres between urban and rural regions. Again, we do not have any good explanation for this.

Our data on seroprevalence of antibodies in children who were not fully vaccinated showed that the antibody response to PV1 and PV2 were comparable with those of fully vaccinated children. However, this may be due to the effect of national immunization days, which were not considered in our calculations of the number of received vaccines for the sake of precision and validity of data.
We found a significant difference between male and female participants in Chabahar with regard to anti-PV3 seroprevalence although we did not find any difference between the sexes with regard to any other demographic and socioeconomic variables, However, we still have to answer the question why the same difference did not occur in the serological response to the other 2 serotypes. Such a difference in the serological status between males and females was not seen for PV1 and PV2 and could not be explained just based on flaws in our sampling scheme, cold-chain or techniques of vaccine administration, or even vaccine quality. More observations and data gathering in future studies is required to confirm that this finding was not a chance one.

As mentioned before, the children who had been exclusively breastfed during the first 6 months of life were about twice as likely to have a seropositive result for PV3. We could not find any similar findings in other studies from other countries, apparently because this has not been studied before. This finding needs further research to confirm it and we suggest the inclusion of questions about breastfeeding history in future studies on vaccines.

We have detailed the sampling scheme and the flaws and pitfalls that occurred during implementation of the study. The main reason for using a stratified sampling method in this study was to ensure that sufficient numbers of eligible children from the study population would be taking part in the study. Considering this purpose we think that the sample was sufficient to satisfy the main objective of the study, i.e. estimation of the seroprevalence of the antipoliovirus antibody in fully vaccinated children. However, most of the unexplained observations were in Chabahar, the area where we have had more problems in sampling. We hope that future studies can resolve whether this was a chance finding or if these observations are the result of poor implementation of the study sampling scheme.

It is clear that there is a real threat posed by the low seroprevalence of antibody against PV3 in the study population, especially in the rural areas. Consolidation of community protection against the threat of wild poliovirus transmission should be among the high priority health interventions in the study area.

\section{Acknowledgements}

The authors thank Dr Ahmad Abbasi, Dr Majid Sartipi and Ms Sussan Mahmoodi for the management of fieldwork and assistance with data collection; Mr Abdolaziz Gharaei, $\mathrm{Mr}$ Mohammad-Hanif Baluch, and $\mathrm{Mr}$ Feiz-Mohammad Atash-Bahar for their invaluable work during the toughest situations in the field; Dr Hamideh Tabatabaie (Assistant Professor of Virology), Ms Maryam Yousefi, Mr Yaghoob Mollaie, Ms Sahar Abbasi, Mr Mohammad Farahmand and Dr Rakhshandeh Nategh (Professor of Virology) for their invaluable hard laboratory work. 
Funding: This study was financially supported by the Centre for Communicable Disease Control, Ministry of Health and Medical Education. (The
Centre for Communicable Disease Control has had no role in study design, in the collection, analysis and interpretation of data; in the writing of the manuscript and in the decision to submit the manuscript for publication.)

Competing interest: None declared.

\section{References}

1. Zahraie SM, Sadrizadeh B, Gouya MM. Eradication of poliomyelitis in Iran, a historical perspective. Iranian Journal of Public Health, 2009, 38(Suppl. 1):124-126.

2. Progress towards interruption of wild polio virus transmission-worldwide, January 2011-March 2012. Morbidity and Mortality Weekly Report, 2012, 61:353-357.

3. Progress towards global interruption of wild poliovirus transmission, January 2011-March 2012. Weekly Epidemiological Record, 2012, 87:195-200.

4. Moussavi T et al. Global polio eradication and the present situation in Iran. Archives of Iranian Medicine, 2012, 15:107-109.

5. The report of the 2006-2007 population census, Sistan-vaBaluchestan Province Tehran, Statistical Centre of Iran, 2010 [in Farsi]. (http://www.amar.org.ir/, accessed 14 February 2014).

6. Fortuin $\mathrm{M}$ et al. Measles, polio and tetanus toxoid antibody levels in Gambian children aged 3 to 4 years following routine vaccination. Transactions of the Royal Society of Tropical Medicine and Hygiene, 1995, 89:326-329.

7. Liu GY, Wang LX, Chang X. [Surveillance on poliomyelitis neutralization antibody level in the border areas in Jilin province.] Zhongguo Ji Hua Mian Yi, 2009, 15:249-250 [in Chinese].

8. Kahn HA, Sempos CT. Statistical methods in epidemiology. Oxford, Oxford University Press, 1989.

9. Bennett $\mathrm{S}$ et al. A simplified general method for cluster-sample surveys of health in developing countries. World Health Statistics Quarterly, 1991, 44:98-106.

10. Manual for the virological investigation of polio. Geneva, World Health Organization, 1997.

11. Agresti A. An introduction to categorical data analysis. New York, John Wiley, 1996.
12. Diedrich S, Claus H, Schreier E. Immunity status against poliomyelitis in Germany: determination of cut-off values in International Units. BMC Infectious Diseases, 2002, 2:2. doi: 10.1186/1471-2334-2-2.

13. El-Sayed $\mathrm{N}$ et al. Survey of poliovirus antibodies during the final stage of polio eradication in Egypt. Vaccine, 2007, 25:50625070.

14. Kohler KA et al. Outbreak of poliomyelitis due to type 3 poliovirus, northern India, 1999-2000: injections a major contributing factor. International Journal of Epidemiology, 2003, 32:272-277.

15. Maldonado YA et al. Host and viral factors affecting the decreased immunogenicity of sabin type 3 vaccine after administration of trivalent oral polio vaccine to rural Mayan children. Journal of Infectious Diseases, 1997, 175:545-553.

16. Reichler MR et al. Increased immunogenicity of oral poliovirus vaccine administered in mass vaccination campaigns compared with the routine vaccination program in Jordan. Journal of Infectious Diseases, 1997, 175 Suppl 1;S198-S204.

17. Reinheimer $\mathrm{C}$ et al. Deficiency of immunity to poliovirus type 3: a lurking danger? BMC Infectious Diseases, 2012, 12:24.

18. Giwa FJ, Olayinka AT, Ogunshola FT. Seroprevalence of poliovirus antibodies amongst children in Zaria, Northern Nigeria. Vaccine, 2012, 30:6759-6765.

19. Parent du Chatelet I et al. Serological response and poliovirus excretion following different combined oral and inactivated poliovirus vaccines immunization schedules. Vaccine, 2003, 21:1710-1718.

20. Jenkins HE et al. Effectiveness of immunization against paralytic poliomyelitis in Nigeria. New England Journal of Medicine, 2008, 359:1666-1674. 